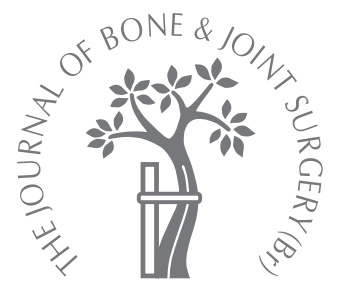
S. Togawa,
N. Yamami,
H. Nakayama,
Y. Mano,
K. Ikegami,
S. Ozeki

From Tokyo Medical and Dental University Hospital Faculty of

Medicine, Tokyo and

Dokkyo University

School of Medicine,

Saitama, Japan

I. Togawa, MD, Research Fellow

H. Nakayama, MD, PhD,

Research Fellow

Y. Mano, MD, PhD,

Chairman

Department of Hyperbaric

Medicine

N. Yamami, MD, PhD,

Associate Professor

Graduate School of Health

Science

Tokyo Medical and Dental

University Hospital Faculty

of Medicine, 1-5-45 Yushima

Bunkyo-Ku, Tokyo 113-5819,

Japan.

- K. Ikegami, MD, PhD, Professor

Trauma and Critical Care

Center

S. Ozeki, MD, PhD,

Orthopaedic Surgeon,

Associate Professor

Department of Orthopaedics

Koshigaya Hospital, Dokkyo

University School of

Medicine, 2-1-50 Minami-

Koshigaya, Koshigaya-city

Saitama 343-8555, Japan.

Correspondence should be sent to Dr S. Togawa; e-mail: stogawa@muc.biglobe.ne.jp

(c)2005 British Editorial

Society of Bone and

Joint Surgery

doi:10.1302/0301-620X.87B11.

$16512 \$ 2.00$

$J$ Bone Joint Surg $[\mathrm{Br}]$

2005;87-B:1516-19.

Received 14 March 2005;

Accepted after revision

1 June 2005

\section{The validity of the mangled extremity severity score in the assessment of upper limb injuries}

The Mangled Extremity Severity Score (MESS) may be used to decide whether to perform amputation in patients with injuries involving a limb. A score of 7 points or higher indicates the need for amputation. We have treated three patients with a MESS of 7 points or higher, in two of which the injured limb was salvaged. This scoring system was originally devised to assess injuries to the lower limb. However, a MESS of 7 points as a justification for amputation does not appear appropriate when assessing injuries to the major vessels in the upper limb.

The Mangled Extremity Severity Score (MESS) $)^{1}$ was originally designed as a standard for deciding on amputation for severe injuries to the lower limb. It allocates points to four aspects of the injury, namely the degree of skeletal or soft-tissue injury, ischaemia of the limb, the degree of shock using a systolic blood pressure of $90 \mathrm{mmHg}$ as a cut-off and the age of the patient. In recent years its application has been expanded to the upper limb but without proper examination of its validity. This study is based on our experience of patients with injuries involving major vessels of the upper limb.

\section{Patients and Methods}

Of 1024 patients seen at our trauma centre from May to December 1999, there were five with injuries to the upper limb involving arteries, three of whom had a MESS of 7 points or higher.

There were two women and one man ranging in age from 26 to 77 years. At the time of arrival at hospital the haemoglobin level was 1.4 to $9.5 \mathrm{mg} / \mathrm{dl}$ and the maximum systolic blood pressure ranged from unmeasurable to $85 \mathrm{mmHg}$. The causes of injury were being trapped in a machine at work, trapped in a vehicle following a road-traffic accident and a self-inflicted crush injury (Table I). The vessels and nerves involved are listed in Table II.

\section{Results}

MESS and treatment. The MESS ranged from 7 to 11 points, including skeletal and softtissue injury classified as 'very high' in two cases and ischaemia of the limb classified as 'pulseless' and 'cool' in one and two cases, respectively (Table III). The ischaemic time in two cases was more than six hours and so the score was doubled.

Amputation was performed in one patient with a MESS of 11 points. The injured limb was salvaged in two cases including the two cases with a MESS of 7 points or higher (Tables III and IV). The amputation was performed in order to achieve early haemostasis since the patient could not be brought out of primary shock and recovery of function was uncertain because of the severity of the injury. In the two limbs which were salvaged, a vein graft was performed, and in one a nerve graft was also used.

In the two patients whose limbs were salvaged, a crush syndrome did not develop. However, the amputee developed disseminated intravascular coagulation but recovered after transfusion and drug treatment.

The final function of the salvaged limb was graded as 2 for two cases using the criteria of Chen et $\mathrm{al}^{2}$ (Table IV).

Limb salvage in patients with a MESS of 7 points or higher

Case 1. A 26-year-old man was trapped in a conveyor belt at a cleaning factory and transferred to our hospital two hours later. On arrival, his systolic blood pressure was 85 $\mathrm{mmHg}$ and the haemoglobin was $9.5 \mathrm{mg} / \mathrm{dl}$. The injury extended from the right axilla to the fingertips. There were multiple fractures of the radius, ulna and metacarpals, skin loss in the upper arm, anterior aspect of the elbow and the palm, and crush injuries to the flexor muscles of the elbow, wrist and fingers. The brachial artery was occluded for about $10 \mathrm{~cm}$ 
Table I. Details of the patients

\begin{tabular}{|c|c|c|c|c|c|c|c|}
\hline Case & Gender* & $\begin{array}{l}\text { Age } \\
\text { (yrs) }\end{array}$ & Occupation & $\begin{array}{l}\text { Time spent until } \\
\text { arrival at hospital } \\
\text { (hrs) }\end{array}$ & $\begin{array}{l}\text { Systolic blood pressure } \\
\text { on arrival at hospital } \\
\text { (mmHg) }\end{array}$ & $\begin{array}{l}\mathrm{Hb}^{\dagger} \text { on arrival at } \\
\text { hospital (mg/dl) }\end{array}$ & Type of injury \\
\hline 1 & $M$ & 26 & Factory worker & 2 & 85 & 9.5 & Trapping \\
\hline 2 & $\mathrm{~F}$ & 27 & Administrator & 14 & 60 & 8.1 & Crush \\
\hline 3 & $\mathrm{~F}$ & 77 & Housewife & 2 & Undetectable & 1.4 & Trapping \\
\hline
\end{tabular}

* F, female; M, male

$\dagger \mathrm{Hb}$, haemoglobin level

Table II. Principal injuries

\begin{tabular}{lllll}
\hline Case & Site of fracture & Injured blood vessels & Injured nerves & Injured muscles/tendons \\
\hline 1 & Radius, ulna, 2nd & Brachial occlusion & None & Flexor tendons to the wrist, fingers and elbow \\
metacarpal, phalanges & $\begin{array}{l}\text { Deep and superficial carpal arches } \\
\text { and the thenar and interosseous muscles }\end{array}$ & Radial and ulnar arteries & Radial and ulnar nerves & Flexor tendons to the wrist and fingers \\
2 & None & Brachial, radial and ulnar arteries & $\begin{array}{l}\text { Musculocutaneous and } \\
\text { median nerves }\end{array}$ & All muscles in the upper arm and forearm \\
\hline
\end{tabular}

Table III. Mangled extremity severity score (MESS) in points

\begin{tabular}{llllll}
\hline Case & $\begin{array}{l}\text { Energy of } \\
\text { the injury }\end{array}$ & Shock & Ischaemia & Age & Total MESS \\
\hline 1 & 4 & 1 & $3 \times 2^{*}$ & 0 & 11 \\
2 & 1 & 2 & $2 \times 2^{*}$ & 0 & 7 \\
3 & 4 & 2 & 3 & 2 & 11 \\
\hline
\end{tabular}

* ischaemic time $>6$ hours, so score is doubled

Table IV. Treatment and outcome

\begin{tabular}{|c|c|c|c|c|}
\hline Case & Blood vessels & Nerves & Muscles/tendons & $\begin{array}{l}\text { Outcome } \\
\text { (point) }\end{array}$ \\
\hline 1 & Two vein grafts & None & $\begin{array}{l}\text { Five tendon } \\
\text { transfers }\end{array}$ & $2^{*}$ \\
\hline 2 & Two vein grafts & Two nerve grafts & Six tendon grafts & $2^{*}$ \\
\hline 3 & Ligature & Amputation & Amputation & Amputation \\
\hline
\end{tabular}

around its division into radial and ulnar vessels because of injury to the endothelium. The deep and superficial arterial (carpal) arches of the palm were injured and there was no blood flow in the fingertips. The MESS was initially judged to total 8 points, with 4 for skeletal/soft-tissue injury, 3 for limb ischaemia, 1 for shock and 0 for age (Figs 1 and 2).

Following open reduction and fixation of the radius and ulna, non-viable tissue was excised. This included biceps, brachialis, the flexors of the wrist, fingers and thumb and the thenar and interosseous muscles. The brachial artery was repaired with a vein graft. By this time, more than six hours had passed since the injury, resulting in a total MESS of 11 points, with doubling of the points for limb ischaemia. The artery in the palm was reconstructed by a vein graft. Skin defects were covered with split-thickness skin grafts in the upper arm and with arterial pedicle skin flaps from the fingertips to the radial side of the hand.

Although development of a crush syndrome was a matter of concern after surgery, with a creatine phosphokinase

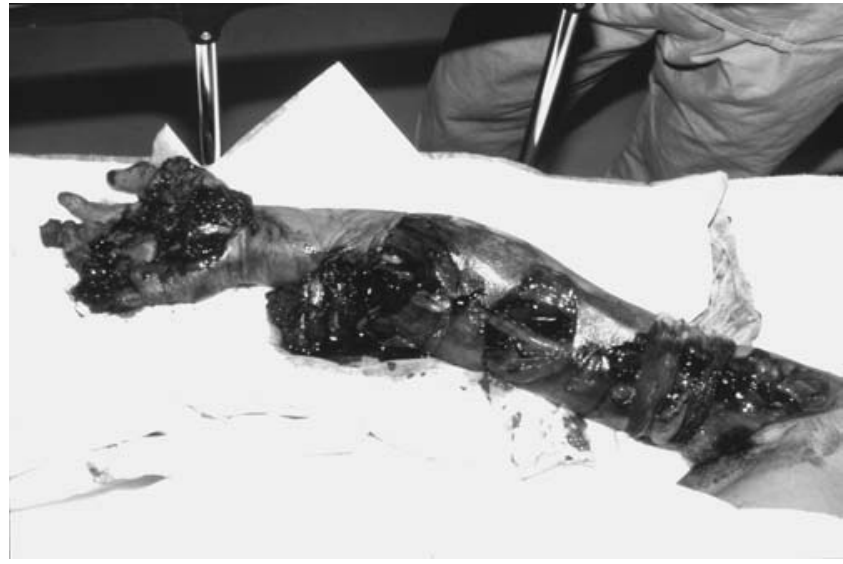

Fig. 1

The injured right upper limb upon arrival at hospital of a 26-year-old man (case 1); the flexor muscles of the elbow and wrist joints are crushed and defective; the brachial artery is in continuity but occluded.

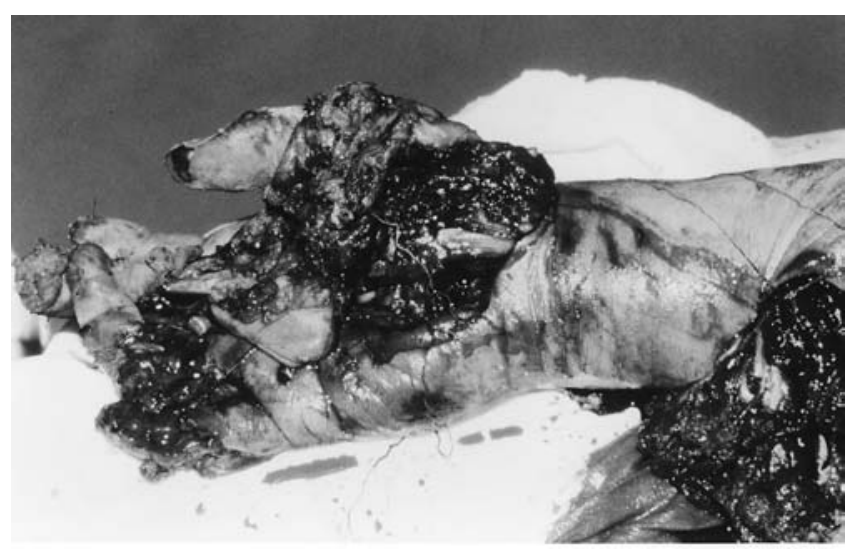

Fig. 2

The hand of a 26-year-old man (case 1). The injury is principally on the palmar side, and the arterial arch is defective. There is damage to the thenar and interosseous muscles with multiple fractures. 


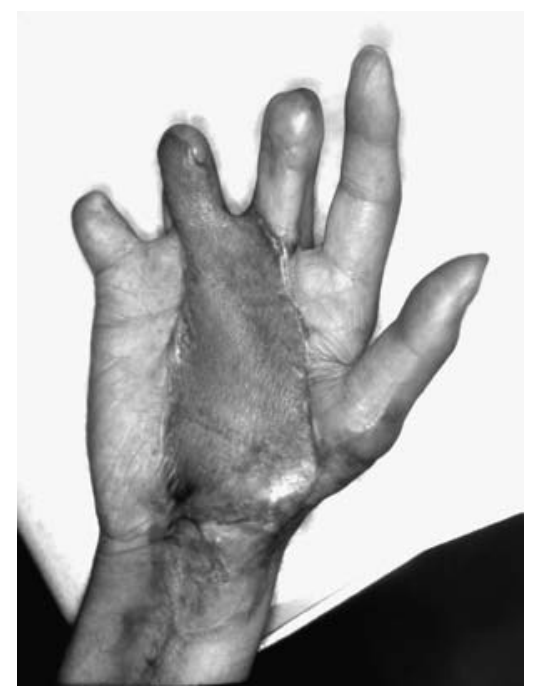

Fig. 3a

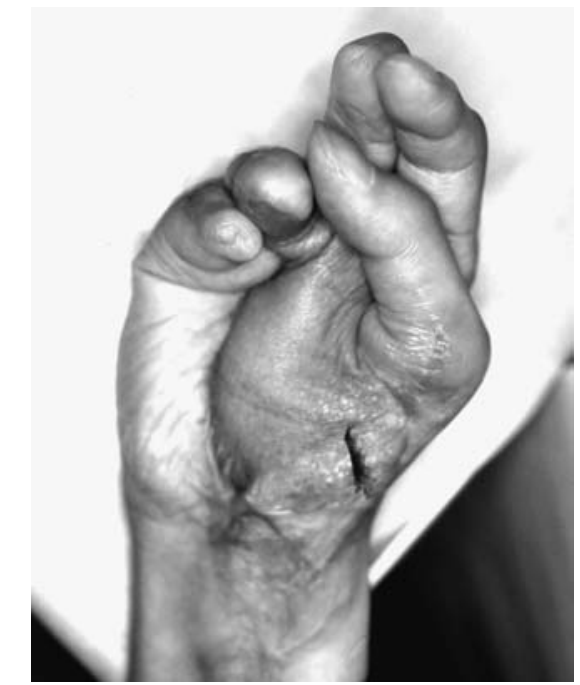

Fig. 3b
Figure 3 - The function of the hand two years after injury (case 1).

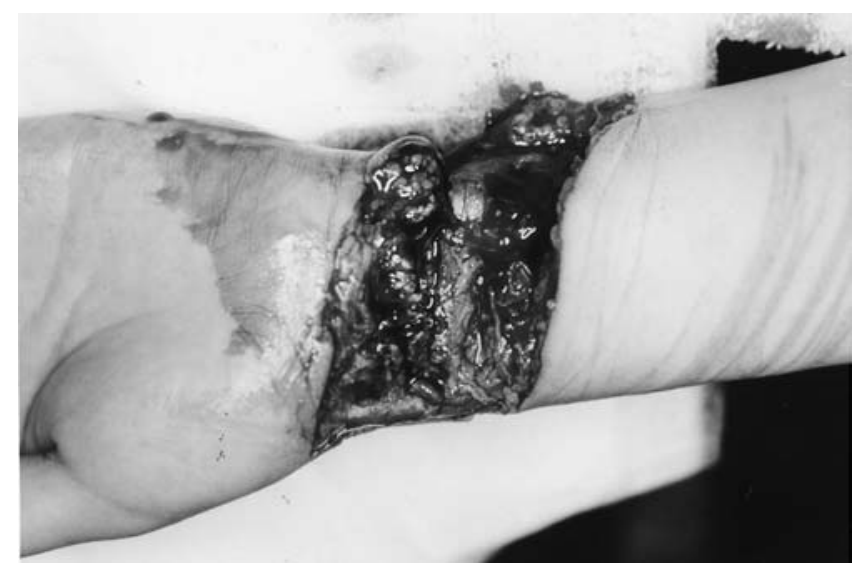

Fig. 4

A laceration at the wrist joint in a 27-year-old woman (case 2). The flexor tendons, the median and ulnar nerves and the radial and ulnar arteries are affected.

exceeding $10000 \mathrm{ul}$, it settled with transfusion and treatment with diuretics. Following subsequent procedures to restore function in the thumb and fingers the limb could be used effectively in day-to-day activities with recovery classed as grade 2 on the Chen classification ${ }^{2}$ (Fig. 3).

Case 2. A 27-year-old woman was found lying on the ground in a park. She had injured herself while drunk between 12 and 15 hours before she was found. On arrival at the hospital she had a haemoglobin of $8.1 \mathrm{mg} / \mathrm{dl}$, a Glasgow Coma Scale of 3; eye opening of 1 , a best verbal response of 1 , a best motor response of 1 , a systolic blood pressure of $60 \mathrm{mmHg}$ and a pulse rate of $180 / \mathrm{min}$. There was a crush injury of the right forearm and to the radial and ulnar arteries, the radial and ulnar nerves and all the flexor tendons were torn and defective (Fig. 4). There was a crushed wound in the neck and the external jugular veins and auricular nerves were torn. The MESS was judged as 1 point for skeletal/soft-tissue injury, 4 ( $2 \times 2)$ points for limb ischaemia, 2 points for shock, and 0 point for age, giving a total of 7 points. The vessels, nerves and tendons were repaired by grafting and the patient was successfully treated for primary shock by massive transfusion of fluid and blood, without the development of a crush syndrome. Following surgery, she was diagnosed as suffering from schizophrenia. Three years after surgery, the range of movement was almost normal in all her fingers, she could oppose the thumb and had some abduction of the little finger. The sensation in the distribution of the median and ulnar nerves had improved and she was judged to be grade 2 by Chen's criteria (Fig. 5).

\section{Discussion}

The decision to perform an amputation in the initial stages of treatment of any of the limbs often depends on the judgment of whether or not a repair is possible. ${ }^{3,4}$ This depends upon the skill of the surgeon and, consequently, there are no standard criteria for this decision. However, it is generally accepted that amputation may be carried out to avoid a crush syndrome, to control bleeding, and to remove the limb as a source of infection. These three factors were present in the two cases we describe, so amputation was an obvious choice and yet the injured limb was successfully salvaged. The MESS was designed by Johansen et $\mathrm{al}^{1}$ to simplify evaluation in an emergency, based upon both direct and indirect factors. It was published as a standard for decisions on amputation of the lower limb and amputation was recommended for cases with a MESS of 7 points or higher. ${ }^{5,6}$ Johansen et $\mathrm{al}^{1}$ considered that the development of objective scoring systems to help predict limb salvage must discriminate between the upper and lower extremities. Subsequently, this system has also been applied 


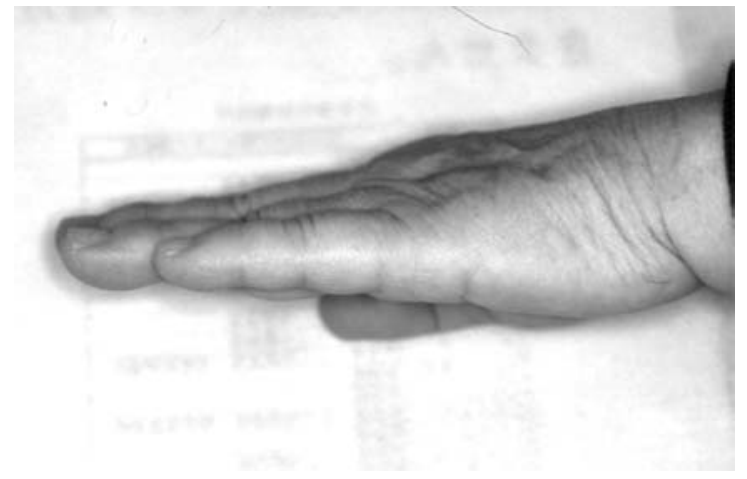

Fig. $5 a$

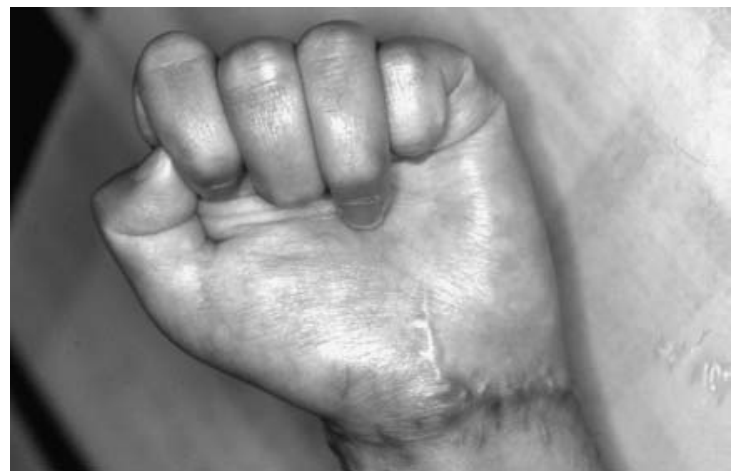

Fig. $5 b$

Almost normal extension and flexion three years after injury (case 2).

to the upper limb and, currently, is applied in many institutions to cases with a score of 7 points or higher, regardless of involvement of the upper or lower limb. ${ }^{7}$ However, for our patients, in whom limb salvage was achieved with scores of 7 and 11 , there is doubt over the value of the MESS in the upper limb. Here the muscle mass is small compared with the lower $\operatorname{limb}^{8}$ and the factors contributing to the development of a crush syndrome are reduced in scale. Because of the well-developed collateral circulation, there is no artery in the upper limb, like the popliteal artery in the lower limb, which produces ischaemia proximally as a result of a single arterial laceration. The level of ischaemia differs in the upper and lower limbs in major arterial injuries. The critical time allowed for reperfusion in the arm is eight to ten hours ${ }^{9,10}$ which negates the six-hour limit for the MESS in the leg. These differences make the MESS score inappropriate for application to the upper limb and it is necessary to establish suitable, alternative standards for this site. ${ }^{11}$ The chance of salvaging a limb increases when ischaemia is improved by hyperbaric oxygen therapy. ${ }^{12,13}$ Surgeons should, therefore, avoid relying on the MESS as a justification for performing amputation of the upper limb when other techniques to repair injuries to blood vessels are available.

No benefits in any form have been received or will be received from a commercial party related directly or indirectly to the subject of this article.

\section{References}

1. Johansen K, Daines M, Howey T, Helfet D, Hansen ST Jr. Objective criteria accurately predict amputation following lower extremity trauma. J Trauma 1990;30: 568-72.

2. Chen ZC, Meyer VE, Kleinert HE, Beasley RW. Present indications and contraindications for replantation as reflected by long-term functional results. Orthop Clin North Am 1981;12:849-70.

3. Hansen ST Jr. The type-IIIC tibial fracture: salvage or amputation. J Bone Joint Surg [Am] 1987;69-A:799-800.

4. Lange RH, Bach AW, Hansen ST Jr, Johansen KH. Open tibial fractures with associated vascular injuries: prognosis for limb salvage. J Trauma 1985;25:203-8.

5. McNamara MG, Heckman JD, Corley FG. Severe open fractures of the lower extremity: a retrospective evaluation of the Mangled Extremity Severity Score (MESS). J Orthop Trauma 1994;8:81-7.

6. Helfet DL, Howey T, Sanders R, Johansen K. Limb salvage versus amputation: preliminary results of the Mangled Extremity Severity Score. Clin Orthop 1990;256:80-6.

7. Slauterbeck JR, Britton C, Moneim MS, Clevenger FW. Mangled extremity severity score: an accurate guide to treatment of the severely injured upper extremity. J Orthop Trauma 1994:8:282-5.

8. Clarys JP, Marfell-Jones MJ. Soft tissue segmentation of the body and fractionation of the upper and lower limbs. Ergonomics 1994;37:217-29.

9. Wang SH, Young KF, Wei JN. Replantation of severed limbs: clinical analysis of 91 cases. J Hand Surg [Am] 1981;6:311-18.

10. Wood MB, Cooney WP 3rd. Above elbow limb replantation: functional results J Hand Surg [Am] 1986;11:682-7.

11. Lin CH, Wei FC, Levin LS, Su JI, Yeh WL. The functional outcome of lower-extremity fractures with vascular injury. J Trauma 1997;43:480-5.

12. Myers RA. Hyperbaric oxygen therapy for trauma: crush injury, compartment syndrome, and other acute traumatic peripheral ischemias. Int Anesthesiol Clin 2000;38:139-51.

13. Bouachour G, Cronier P, Gouello JP, et al. Hyperbaric oxygen therapy in the management of crush injuries: a randomized double-blind placebo-controlled clinical trial. J Trauma 1996;41:333-9. 